\title{
DIETARY PROBIOTIC Lactobacillus plantarum L-211 FOR FARM ANIMALS. II. THE ADDITIVE FOR PIGLETS
}

\section{V.I. FISININ', E.A. ARTEM'EVA², I.I. CHEBOTAREV³, G.Yu. LAPTEV4, I.N. NIKONOV 4 , L.A. IL'INA ${ }^{4}$, N.G. MASHENTSEVA ${ }^{5}$, A.V. SAVINOV 3 , D.L. KLABUKOVA ${ }^{5}$, E.A. YILDIRIM ${ }^{4}$, N.I. NOVIKOVA ${ }^{4}$}

\author{
${ }^{1}$ Federal Scientific Center All-Russian Research and Technological Poultry Institute RAS, Federal Agency of Scientific \\ Organizations, 10, ul. Ptitsegradskaya, Sergiev Posad, Moscow Province, 141315 Russia, e-mail olga@vnitip.ru; \\ ${ }^{2}$ L.K. Ernst All-Russian Research Institute of Animal Husbandry, Federal Agency of Scientific Organizations, 60, pos. \\ Dubrovitsy, Podolsk District, Moscow Province, 142132 Russia, e-mail vijinfo@yandex.ru; \\ 2JSC «Bioreactor», 18, ul. Komarova, Shchelkovo, Moscow Province, 114142 Russia; \\ ${ }^{4} J S C$ «Biotrof», Kolpino, St. Petersburg, 192288 Russia, e-mail nikonov@biotrof.ru (corresponding author);

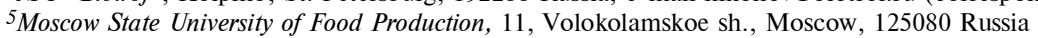 \\ ORCID: Fisinin V.I. orcid.org/0000-0003-0081-6336 \\ The authors declare no conflict of interests \\ Acknowledgements: \\ Supported financially under the subsidy agreement with Ministry of Education and Science of the Russian Federa- \\ tion № 14.579.21.0021 dated 05.06.2014
}

Received October 3, 2016

\section{Abstract}

The lack of lysine in the diet of pigs negatively affects appetite, weight gain, metabolism and immunity of animals. Most feeds for pigs are deficient in lysine. Synthetic amino acids, as feed additives, make feeds significantly more expensive. In this regards, the biologcs based on microbial producers able to synthetize lysine in the gastrointestinal tract of animals are promising. However, common producers of lysine, Brevibacterium lactofermentum, Escherichia coli and the genus Corynebacterium, are conditionally pathogenic as a causal agents of opportunistic infections. In the present study, we first examined the changes in intestinal bacterial community and the productive performance in Large White pigs («Novgorod bacon», Novgorod Province) under the influence a lysine producing strain Lactobacillus plantarum L-211 (JSC «Bioreactor», Moscow). Taxonomic composition of microorganisms was determined by T-RFLP (terminal restriction fragment length polymorphism) analysis. For surveillance we used two groups of pigs from 28- to 84-day age, fed with the basic diet $(n=715$, group 1, control) and the same diet supplemented with $L$. plantarum L211 at the dose not less than $10^{9} \mathrm{CFU}$ per animal added to water $(n=657$, group 2$)$. Microbial community in the pigs' large intestine was taxonomically divers and included a number of unidentified phylotypes. Here, the predominating bacteria were representatives of the phylum Firmicutes, including mainly Clostridia possessing cellulolytic and amylolytic properties, as well as the members of order Negativicutes able to ferment acids. The phyla Proteobacteria, Bacteroidetes, Actinobacteria and Fusobacteria were less abundant. The counts of genus Lactobacillus was lower than previously assumed, moreover, there was a complete absence of enterococci and bifidobacteria, which are usually attributed to the autochthonous microbiota of the large intestine of animals and birds. Lysine synthesizing strain $L$. plantarum L-211 had a high probiotic effect resulting in a significant increase in the counts of genera Lactobacillus (2.94-fold, $\mathrm{P}<0.01)$ and Bacillus (3.29fold, $\mathrm{P}<0.01$ ), of phylum Bacteroidetes (5.29-fold, $\mathrm{P}<0.01$ ), and class Clostridia $(2.05$-fold, $\mathrm{P}<0.01$ ), whereas the proportions of pathogens from Staphylococcus genus and Campylobacteriaceae family were below the T-RFLP sensitivity, and the family Pasteurellaceae decreased in number 1.41-fold $(\mathrm{P}<0.05)$. Both the survival and the average daily weight gain $(\mathrm{P}<0.05)$ in pigs, as influenced by the probiotic strain L. plantarum L-211, were higher. L. plantarum L-211 also improved feed conversion efficiency as compared to the control pigs.

Keywords: lysine, intestinal microflora, pigs, bacterial community, T-RFLP, probiotic, Lactobacillus plantarum, productivity, pigs' survival, feed conversion

In baby pigs, digestive system is formed and live weight is intensively incresed which is important for obtaining highly productive livestock [1, 2]. In this, full amino acid composition of the diet, including essential amino acids, plays a special role. The lack of lysine is associated with a decrease in appetite and productivity of animals, weight loss, impaired calcification of bones, general 
exhaustion and anemia [3, 4]. In addition, immunity suppression occurs and susceptibility to infectious diseases increases [5]. Due to the lack of lysine in vegetable fodder mixtures, their use in feeding pigs is ineffective. The main raw materials in production of domestic mixed fodders for pigs are the components deficient in the lysine (grain, by-products of their processing, sunflower meal), therefore, as a rule, it is not possible to provide enough lysine level without the use of synthetic amino acids, which considerably increases the fodder cost [6, 7].

The development of probiotics synthesizing lysine in the gastrointestinal tract of animals $[8,9]$ performed in Russia and abroad, are considered as the most promising approach in the formation of the optimal intestinal microflora. In this, Brevibacterium lactofermentum, Escherichia coli and representatives of the genus Corynebacterium [10-12] were mainly studied as lysine producers, but the listed microorganisms are conditionally pathogenic and capable of causing opportunistic infections, so their use as probiotics is undesirable. Some strains of the genus Lactobacillus are also able to synthesize lysine $[8,9,13]$ and positively affect growth, carcass quality, animal immunity $[14,15]$. The positive effect of dietary lactobacilli in pigs is also associated with the synthesis of organic acids and bacteriocins that inhibit the growth and development of various pathogens, i.e. Salmonella, Proteus, Staphylococcus, E. coli, Pseudomonads, Streptococci $[15,16]$.

In recent years, successful use of molecular genetic approaches to study the microbial community of the digestive tract of pigs has been reported, including differences in the composition of microbiocenosis of healthy pigs and animals with intestinal disorders [17, 18]. The T-RFLP (terminal restriction fragment length polymorphism) and NGS (next generation sequencing) methods allow a detailed description of the microbial community, revealing not only taxonomic dominants, but also minor components, including non-cultivated microorganisms, whose proportion in different ecosystems can reach $90 \%$ [19, 20[. However, studies of the intestinal microbiom of pigs carried out to date are extremely few [21, 22], and data on the complex analysis of the bacterial community, as influenced by probiotic lactobacilli, are absent. The strain Lactobacillus plantarum L-211 is described as a lysine producer with a fairly high yield in culture [8,9].

For the first time, using the T-RFLP method, we determined the composition of the bacterial community in the thick intestine of the baby pigs when the preparation of the lysine-producing strain of lactobacilli was supplemented with water and revealed its high probiotic activity which was accompanied by positive changes in the zootechnical indices, i.e. an increased survivability and daily live weight gain.

The purpose of this work was to study the effect of dietary lysineproducing strain Lactobacillus plantarum L-211 on the bacterial community of the intestine and the productive indices in baby pigs during early growth.

Technique. Farm experiment was carried out on two groups of baby Large White pigs from day 28 to day 84 of life (OOO Novgorodsky Bacon, Novgorod region). The feeding and housing pigs from groups I (control, $n=715$ ) and II $(n=657)$ were in compliance with all technological parameters and equivalent feed compositions (OOO Novgorodsky Bacon, Novgorod region) for lysine corresponding to the norms for Large White breed. Baby pigs of group II were additionally given dietary Lactobacillus plantarum L-211 (OOO Bioreactor, Moscow) in a dose of at least $10^{9} \mathrm{CFU}$ per animal. Survivability of livestock, the live weight of baby pigs at the age of 28 and 84 days in individual weighing, its daily gain, feed consumption and feed costs per $1 \mathrm{~kg}$ of live weight were recorded.

Contents of the large intestine from three slaughtered pigs of each group were collected on day 84 with strict sterility for molecular genetic studies. TRFLP analysis of bacterial community was performed according to description 
[23]. Total DNA was isolated from the samples using Genomic DNA Purification Kit (Fermentas, Inc., Lithuania) according to manufacturer's recommendations. PCR was performed on a Verity DNA amplifier (Life Technologies, Inc., USA) with eubacterial primers 63F CAGGCCTAACACATGCAAGTC labeled at the 5'-end (WellFed D4 fluorophore, Beckman Coulter, Inc., USA) and 1492R TACGGHTACCTTGTTACGACTT. The fluorescently labeled amplicons of 16S rRNA gene was purified as described [24], the restriction (30-50 ng DNA) with endonucleases HaeIII, HhaI and MspI was performed following the manufacturer's recommendation (Fermentas, Inc., Lithuania). Restricts were analyzed using CEQ ${ }^{\mathrm{TM}} 8000$ (Beckman Coulter Inc., USA) according to the manufacturer's protocol. The taxonomic attribution was performed in the Fragment Sorter program (http://www.oardc.ohiostate.edu/trflpfragsort/index.php).

The data were processed by an analysis of variance. Differences with the control were considered significant at $\mathrm{P}<0.05 ; \mathrm{P}<0.01$ and $\mathrm{P}<0.001$.

Results. T-RFLP analysis of the microbial community of thick intestine where the most important digestion of carbohydrates, including fiber, occurs with participation of intestinal microbiota and formation of volatile fatty acids (VFA) and other metabolites [25], revealed a number of taxonomic groups (Table 1).

1. The ratio of bacterial taxa $(\%)$ in the thick intestine in 84-day old the Large White pigs receiving probiotic Lactobacillus plantarum $\mathrm{L}$ 211 ( $X \pm x$, OOO Novgorodsky bacon, Novgorod region)

\begin{tabular}{|c|c|c|}
\hline Taxon & $\begin{array}{l}\text { Group I (con- } \\
\text { trol, } n=3 \text { ) }\end{array}$ & $\begin{array}{l}\text { Group II } \\
(n=3)\end{array}$ \\
\hline Phylum Bacteroide & $0.17 \pm 0.01$ & $0.90 \pm 0.04^{* *}$ \\
\hline Firmicutes & $35.46 \pm 1.69$ & $65.38 \pm$ \\
\hline Clostridia & $5.35 \pm 0$ & $10.96 \pm$ \\
\hline Lachnospirc & $1.48 \pm 0$ & 0.69 \\
\hline Eubacte & $1.07 \pm 0$ & $8.18=$ \\
\hline Rumi & \pm 0 & $.02 * *$ \\
\hline у Clostric & \pm 0 & $1.62 \pm$ \\
\hline Peptos & \pm 0 & Brd \\
\hline Lac & 7. & $23.07 \pm$ \\
\hline$B a c$ & & $9.65 \pm 0$. \\
\hline Sto & 0.2 & Brd \\
\hline & 19. & $21.70 \pm 1.03$ \\
\hline Phylum Actinobac & 0 & Brd \\
\hline Proteobc & 3 & $.06^{* *}$ \\
\hline Fnt & 3 & $1.95 \pm 0.15^{*}$ \\
\hline fa & & \\
\hline family Pseudor & $0.96 \pm 0.04$ & $0.21 \pm 0.01^{* * *}$ \\
\hline Acinetol & Brd & $0.48 \pm 0.02$ \\
\hline & $0 \pm 0$. & 1.84 \\
\hline Fusobacteria & & $0.14 \pm 0.01^{*}$ \\
\hline Und & $59.49 \pm 2.98$ & $29.10 \pm 1.39 * *$ \\
\hline \multicolumn{3}{|c|}{$\begin{array}{l}\text { Not e. Description of the groups is given in the Technique section. } \\
\text { Brd - below the limit of reliable determination by the method of } \\
\text { T-RFLP (terminal restriction fragment length polymorphism). } \\
\text { *, **, *** Differences with control are statistically significant at } \\
\mathrm{P}<0.05, \mathrm{P}<0.01 \text { and } \mathrm{P}<0.001 \text {, respectively. }\end{array}$} \\
\hline
\end{tabular}

Identified bacteria belonged to five phylums, of which the members of the phylum Firmicutes, including Clostridia and the order of Negativicutes, predominated. Traditionally, the bacteria of the families Lachnospiraceae, Clostridiaceae, Ruminococcaceae, Eubacteriaceae belonging to class Clostridia, are considered as the main producers of enzymes (cellulase, hemicellulase, amylase, etc.) necessary to metabolize carbohydrates from plant fodder. As a rule, the VFAs formed during this process are used by representatives of the order of Negativicutes, including bacteria Megasphaera, Selenomonas, and others. Note that these processes were previously described primarily for ruminants [25]. The phyla of Proteobacteria, Bacteroidetes, Actinobacteria and Fusobacteria were less abundant.

Some gut microorganisms found were opportunistic and pathogenic. Bacteria of the genus Fusobacterium, revealed in both groups, have traditionally been regarded as causative agents of cattle necrobacteriosis [26], and their presence in the intestine, various organs, on the skin in animals and humans has now been confirmed using molecular genetic methods [27]. Representatives of the families Enterobacteriaceae and Campylobacteriaceae detected in the intestine in small quantities are typical pathogens of the dysbiosis in animals. Of interest is the fact that bacteria of the family Pasteurellaceae, the pathogens of respiratory tract in animals and poultry, have been detected in the intestines of baby pigs 
[16]. At that, bacteria of the genus Staphylococcus common in intestinal contents of animals were practically absent in baby pigs.

A part of the bacterial community could not be taxonomically identified which agrees with foreign and domestic studies of the microbiom of the digestive tract in various species of animals and poultry [23, 28]. As to the identified bacteria, the results obtained using the T-RFLP method also did not contradict the known concepts [16, 21, 25] with some exceptions. Thus, the bacteria of the genus Lactobacillus, which are commonly considered to be the dominant inhabitants of pig intestines, we found in small amounts. In addition, enterococci and bifidobacteria, previously described as representatives of the autochthonous microbiota of the large intestine in animals and birds, were completely absent in the intestines of these baby pigs [16, 21].

Dietary probiotic L. plantarum L-211 which produces an average of $148.4 \pm 4.45 \mathrm{mg} / \mathrm{l}$ lysine in minimal media culture [8, 9], when given with water to pigs once a week at a dose of at least $10^{9} \mathrm{CFU}$ per animal, changed microbiota of the large intestine. The percentage of genus Lactobacillus representatives increased 3 times $(\mathrm{P}<0.01)$, which was probably due to the good persistence and growth of the introduced lactobacilli in intestinal contents. The ability of a number of lactobacilli to adhere to the intestinal walls is known which allows them to colonize the digestive tract [29] and occupy free ecological niches in its microbiome, exerting a probiotic effect. In addition, L. plantum strain L-211 contributed to a 3-fold increase in the number of bacteria of genus Bacillus $(\mathrm{P}<0.01)$ which also, due to the synthesis of organic acids and bacteriocins, are capable of competitive exclusion of pathogens [16]. L. plantarum L-211 also affected the multiplication of bacteria from the phyla Bacteroidetes and Clostridia, producing cellulolytic and amylolytic enzymes, and caused 5-fold $(\mathrm{P}<0.01)$ and 2 -fold $(\mathrm{P}<0,01)$ increase, respectively, in their number in the large intestine compared to control. The proportion of bacteria from the order Negativicutes under the influence of probiotic lactobacilli did not change significantly.

2. Zootechnical indices in 84-day-old Large White pigs receiving probiotic Lactobacillus plantarum L-211 $(X \pm x$, OOO Novgorodsky bacon, Novgorod region)

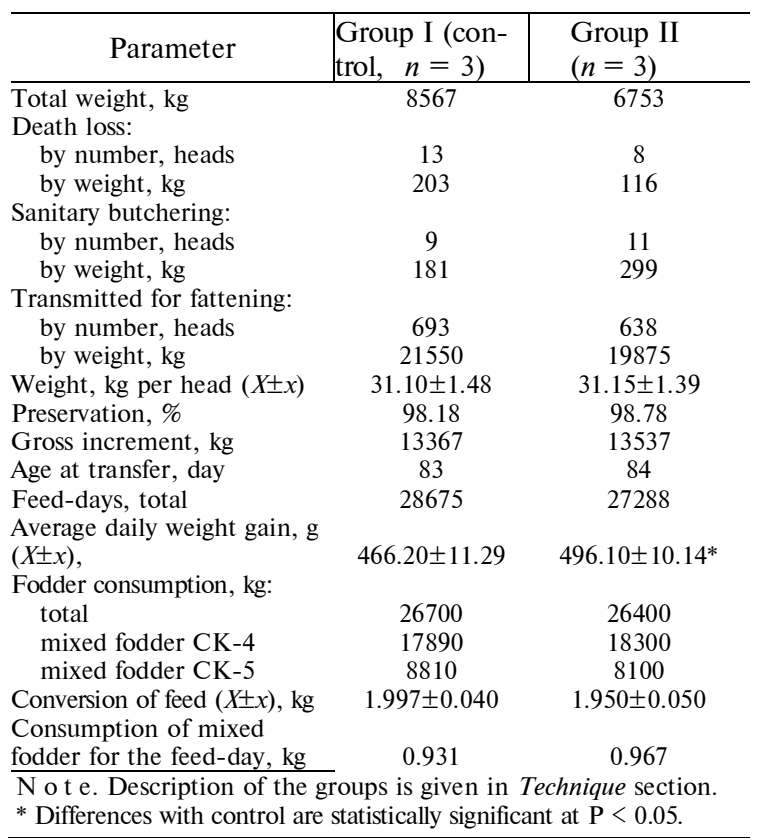

Importantly, L. plantarum L-211 positively affected opportunistic and pathogenic bacteria which percentage decreased. The counts of Staphylococcus and Campylobacteriaceae bacteria decreased to the levels not detectable by T-RFLP, and the Pasteurellaceae was 1.41-fold less abundant $(\mathrm{P}<0.05)$. Also, the counts of Pseudomonadaceae bacteria, transit microorganisms entering intestine with food, decreased 4.57 times $(\mathrm{P}<0.001)$. Unidentified bacteria decreased 2.05 times $(\mathrm{P}<0.01)$ compared to control.

Zootechnical indicators (Table 2) confirmed an increased viability, the daily weight gain $(\mathrm{P}<0.05)$, and the efficiency of feed conversion due to L. plantarum L-211.

Thus, Lactobacillus plan- 
tarum L-211 synthesizing lysine has a high probiotic activity with a positive effect on the composition of the bacterial community of the large intestine of baby pigs. When feeding the probiotic, the normoflora (genera Lactobacillus and $\mathrm{Ba}$ cillus) significantly increased, and the number of microorganisms traditionally associated with intestinal dysbiosis in humans and animals (the family Campylobacteriaceae, Pasteurellaceae, genus Staphylococcus) decreased. The change in the microbial community positively affected zootechnical indicators of pigs which survivability and the daily weight gain $(\mathrm{P}<0.05)$ increased at better feed conversion. Therefore, this probiotic used during early growing can provide for highly productive livestock and reduces the costs of compound feed per unit of production.

\section{REFEREN C ES}

1. G e o rgi e v s ki i V.I. Fiziologiya sel'skokhozyaistvennykh zhivotnykh [Physiology of farm animals]. Moscow, 1990 (in Russ.).

2. Ernst L.K., Laptev G.Yu. Optimizatsiya mikroflory zheludochno-kishechnogo trakta sel'skokhozyaistvennykh zhivotnykh [Gut microflora optimization in farm animals]. St. Petersburg, 2011 (in Russ.).

3. Hulshof T.G., van der Poel A.F., Hendriks W.H., Bikker P. Amino acid utilization and body composition of growing pigs fed processed soybean meal or rapeseed meal with or without amino acid supplementation. Animal, 2016, 5: 1-11 (doi: 10.1017/S1751731116002548).

4. Gallo L., Dalla Bona M., Carraro L., Cecchinato A., Carnier P., Schia v o n S. Effect of progressive reduction in crude protein and lysine of heavy pigs diets on some technological properties of green hams destined for PDO dry-cured ham production. Meat Sci., 2016, 121: 135-140 (doi: 10.1016/j.meatsci.2016.06.005).

5. Craig A., Henry W., Magowa $\mathrm{n}$ E. Effect of phase feeding and valine-to-lysine ratio during lactation on sow and piglet performance. J. Anim. Sci., 2016, 94(9): 3835-3843 (doi: 10.2527/jas.2016-0648).

6. Normy i ratsiony kormleniya sel'skokhozyaistvennykh zhivotnykh. Spravochnoe posobie /Pod redaktsiei A.P. Kalashnikova, V.I. Fisinina, V.V. Shcheglova, N.I. Kleimenova [Norms and rations of feeding of farm animals. Reference Manual. A.P. Kalashnikov, V.I. Fisinin, V.V. Shcheglov, N.I. Kleimenov (eds.)]. Moscow, 2003 (in Russ.).

7. Hulsh of T.G., Poel A.F., Hendriks W.H., B ik ker P. Amino acid utilization and body composition of growing pigs fed processed soybean meal or rapeseed meal with or without amino acid supplementation. Animal, 2016, Dec 5: 1-11 (doi: 10.1017/S1751731116002548).

8. Fisinin V.I., Chebotarev I.I., Nikonov I.N., I1'ina L.A., Laptev G.Yu., M a s he n ts e va N.G. Biofarmatsevticheskii zhurnal, 2014, 6(6): 60-64 (in Russ.).

9. Il'ina L.A., Iyldyrym E.A., Filippova V.A., Nikonov I.N., Laptev G.Yu., Novikova N.I., Fisinin V.I., Chebotarev I.I., Mashentseva N.G., K 1 a b u k o v a D.L. Biofarmatsevticheskii zhurnal, 2015, 7(6): 11-15 (in Russ.).

10. Lal P.B., Schneider B.L., Vu K., Reitzer L. The redundant aminotransferases in lysine and arginine synthesis and the extent of aminotransferase redundancy in Escherichia coli. Mol. Microbiol., 2014, 94(4): 843-856 (doi: 10.1111/mmi.12801).

11. Zhou L.B., Zeng A.P. Exploring lysine riboswitch for metabolic flux control and improvement of L-lysine synthesis in Corynebacterium glutamicum. ACS Synth. Biol., 2015, 4(6): 729-734 (doi: 10.1021/sb500332c).

12. Xing Y., Wang S., Fan J., O s o A.O., Kim S.W., Xiao D., Yang T., Liu G., Jiang G., Li Z., Li L., Z h a ng B. Effects of dietary supplementation with lysine-yielding Bacillus subtilis on gut morphology, cecal microflora, and intestinal immune response of Linwu ducks. J. Anim. Sci., 2015, 93(7): 3449-3457 (doi: 10.2527/jas.2014-8090).

13. Odunfa S.A., Adeniran S.A., Teniola O.D., Nordstrom J. Evaluation of lysine and methionine production in some Lactobacilli and yeasts from Ogi. Int. J. Food Microbiol., 2001, 63(1-2): 159-163.

14. D e li a E., T a f a j M., M ä n n e r i n K. Efficiency of probiotics in farm animals. In: Probiotic in animals. E. Rigobelo (ed.). InTech., 2012. V. 2: 247-272 (doi: 10.5772/50055).

15. Li P., Li X., Gu Q., L o u X.Y., Z hang X.M., S o ng D.F., Z hang C. Comparative genomic analysis of Lactobacillus plantarum ZJ316 reveals its genetic adaptation and potential probiotic profiles. J. Zhejiang Univ. Sci. B, 2016, 17(8): 569-579 (doi: 10.1631/jzus.B1600176).

16. Seo B.J., Mun M.R., Rejish Kumar V.J., K i m C.-J., Le e I., Chang Y.-H., Park Y.H. Bile tolerant Lactobacillus reuteri isolated from pig feces inhibits enteric bacterial pathogens and porcine rotavirus. Vet. Res. Commun., 2010, 34(4): 323-333 (doi: 10.1007/s11259-010-9357-6).

17. P a ja ri 11 o E.A., $\mathrm{C} h$ a e J.P., B a lo lo ng M.P., K i m H.B., S e o K.S., K a ng D.-K. Characterization of the fecal microbial communities of Duroc pigs using 16S rRNA gene py- 
rosequencing. Asian-Australas. J. Anim. Sci., 2015, 28: 584-591 (doi: 10.5713/ajas.14.0651).

18. Vondruskova H., S la mova R., Trckova M., Zraly Z., Pavlik I. Alternatives to antibiotic growth promoters in prevention of diarrhoea in weaned piglets: A review. Veterinarni Medicina, 2010, 55(5): 199-224.

19. Dicksved J., Floistrup H., Bergstrom A., Rosenquist M., Pershagen G., Scheynius A., Roos S., Alm J.S., Engstrand L., Braun-Fahrlander C., von Mutius E., Jansson J.K. Molecular fingerprinting of the fecal microbiota of children raised according to different lifestyles. Appl. Environ. Microbiol., 2007, 73: 2284-2289 (doi: 10.1128/AEM.02223-06).

20. Davis E., Rehberger J., King M., Brown D.C., M axwe 11 C.V., Re hberger T. Characterization of gastrointestinal microbial and immune populations post-weaning in conventionally-reared and segregated early weaned pigs (Proc. 11 ${ }^{\text {th }}$ Int. Symp. on Digestive Physiology of Pigs, Costa Daurada, 2009). Livestock Sci., 2010, 133: 92-94 (doi: 10.1016/j.livsci.2010.06.032).

21. Cha e J.P., P a ja ri 11 o E.A., O h J.K., Ki m H., K a ng D.K. Revealing the combined effects of lactulose and probiotic enterococci on the swine faecal microbiota using 454 pyrosequencing. Microbial Biotechnology, 2016, 9: 486-495 (doi: 10.1111/1751-7915.12370).

22. D i c k s ve d J., J a n s s o n J.K., Li n d b e rg J.E. Fecal microbiome of growing pigs fed a cereal based diet including chicory (Cichorium intybus L.) or ribwort (Plantago lanceolata L.) forage. Journal of Animal Science and Biotechnology, 2015, 6: 53 (doi: 10.1186/s40104-015-0054-8).

23. Laptev G.Yu., Novikova N.I., Il'ina L.A., Iyldyrym E.A., Nagornova K.V., Dumova V.A., Soldatova V.V., Bol'shakov V.N., Gorfunkel' E.P., Dubrovina E.G., S o kolova O.N., N i k o n o v I.N., L e b e d e v A.A. Normy soderzhaniya mikroflory $v$ rubtse krupnogo rogatogo skota [Norms of rumen microflora in cattle]. St. Petersburg, 2014 (in Russ.).

24. Maniatis T., Fritsch E.F., Sambrook J. Molecular cloning: A laboratory manual. Cold Spring Harbor, NY, 1982.

25. T a ra k a n o v B.V. Metody issledovaniya mikroflory pishchevaritel'nogo trakta sel'skokhozyaistvennykh zhivotnykh $i$ ptitsy [Methods for studying the microflora of the digestive tract in agricultural animals and poultry]. Moscow, 2006 (in Russ.).

26. N o c e k J.E. Bovine acidosis: implications on laminitis. J. Dairy Sci., 1997, 80: 1005-1028 (doi: 10.3168/jds.S0022-0302(97)76026-0).

27. Encyclopedia of metagenomics: environmental metagenomics. S.K. Highlander, F. RodriguezValera, B.A. White (eds.). Springer US, NY, 2015.

28. K rale r M., G ha n b a r i M., D o m i g K.J., S c h e d l e K., K n e i f e l W. The intestinal microbiota of piglets fed with wheat bran variants as characterised by $16 \mathrm{~S}$ rRNA next-generation amplicon sequencing. Arch. Anim. Nutr., 2016, 70(3): 173-189 (doi: 10.1080/1745039X.2016.1160534).

29. Ku can M., Gobin I., Markov K., J u r c i c Mom cilovi c D., Fre c e J. Testing the adhesion and colonization ability of Lactobacillus plantarum strain $\mathrm{S} 1$ to the mice intestinal epithelium. International Journal of Sanitary Engineering Research, 2012, 6(1): 25-30. 